\title{
A BUSCA DA FORMALIZAÇÃO JURÍDICA COMO FORMA DE SUPLANTAR OS FREIOS CAPITALISTAS À CONSOLIDAÇÃO DA ECONOMIA POPULAR E SOLIDÁRIA
}

\author{
Emile Lima Oliveira ${ }^{1}$ \\ 1. Bolsista PROBIC/UEFS, Graduanda em Direito, Universidade Estadual de Feira de Santana, e-mail: \\ emile_256@hotmail.com
}

PALAVRAS-CHAVE: Economia Solidária; Consolidação; Formalização Jurídica.

\section{INTRODUÇÃO}

$\mathrm{Na}$ medida em que as iniciativas de Economia Popular e Solidária atrelam-se, essencialmente, ao condomínio dos meios de produção, à repartição substancialmente igualitária do produto do trabalho e às formas democráticas e autogestionárias de organização - desafiando, portanto, a forma hegemônica de produção -, a população que delas se beneficia depara-se com uma diversidade de mecanismos inibidores, dentre os quais se destaca a ausência de formas jurídicas adequadas à aquisição de personalidade jurídica pelos grupos envolvidos. Neste vértice, sem o apropriado reconhecimento jurídico estatal, outros entraves são desencadeados, tais como falta de acesso às políticas públicas, formalização demasiadamente onerosa e complexidade dos procedimentos tributários e contábeis.

Inserida neste contexto, a Incubadora de Iniciativas da Economia Popular e Solidária da Universidade Estadual de Feira de Santana (IEPS-UEFS) desenvolve projetos de incubação de dois grupos informais, os quais atuam na comercialização de lanches nos espaços das cantinas do módulo I e VII da citada universidade. Neste âmbito, a formalização jurídica, essencial à firmação de negócios com o poder público/instituições bancárias e à regularização previdenciária dos integrantes, tem sido um árduo desafio, tanto para os grupos incubados, quanto para a equipe da Incubadora.

Tal pesquisa destina-se, portanto, à identificação de caminhos menos burocráticos e alternativos, dentro do sistema jurídico vigente, para a formalização jurídica de iniciativas de Economia Popular e Solidária (especialmente daquelas desenvolvidas no âmbito da IEPSUEFS), tendo em vista sua consolidação e sobrevivência.

\section{MATERIAL E MÉTODOS OU METODOLOGIA (ou equivalente)}

Adotou-se, aqui, a metodologia de pesquisa exploratória, eis que, para fins de maior compreensão da problemática envolvida na formalização jurídica dos grupos de produção não capitalista, foi realizado não só um levantamento de dados por meio da pesquisa bibliográfica e documental (máxime do ordenamento jurídico em vigor), colhendo-se, também, informações perante os órgãos públicos relacionados à formalização (Secretarias da Fazenda, Tabelionatos, Junta Comercial etc.), reunindo dados relativos aos seus trâmites reais.

Ademais, já que a proposta era de uma pesquisa participante, foram realizadas rodas de conversa com os grupos incubados pela IEPS-UEFS, relacionando-se as informações colhidas com a realidade dos grupos incubados. 
Insta consignar, por fim, que também realizou-se uma espécie de conversação com outros grupos ligados à Economia Popular e Solidária - com áreas de atuação externas ao âmbito da IEPS-UEFS -, compartilhando experiências e firmando parcerias.

\section{RESULTADOS E/OU DISCUSSÃO (ou Análise e discussão dos resultados)}

A pesquisa constituiu-se, inicialmente, na leitura e análise do referencial teórico adotado e do ordenamento jurídico pátrio, pelo que se buscou encontrar caminhos menos burocráticos e alternativos para a formalização do grupo incubado (COPERMASOL), haja vista a imprescindibilidade de tal processo à firmação de negócios com o poder público/instituições bancárias e à regularização previdenciária das integrantes.

Corroborando com a pesquisa bibliográfica e documental acima apontada, também se analisou a realidade vivenciada pelos grupos de Economia Popular e Solidária (especialmente a partir de reuniões ordinárias, realizadas semanalmente, e outras atividades do Programa), conduzindo a pesquisa a resultados que se compatibilizassem com as necessidades e peculiaridades desse modo de produção.

Com efeito, associando-se os produtos até então alcançados, passou-se à construção do contrato social do grupo incubado, desenvolvido com base nos preceitos da Economia Solidária e em parceria entre a pesquisadora, a orientadora, as integrantes do referido grupo e outros bolsistas da Incubadora de Iniciativas da Economia Popular e Solidária da UEFS (IEPS-UEFS).

A partir do reportado instrumento contratual, constituiu-se uma sociedade simples pura, cujo nome social é "COMPANHEIRAS DE MÃOS SOLIDÁRIAS COPERMASOL SOCIEDADE SIMPLES”.

Após ser devidamente assinado, o contrato foi levado a registro no Cartório de Registro de Pessoas Jurídicas deste município. Tal processo revelou-se exacerbadamente intricado, especialmente pela grande quantidade de taxas que tiveram que ser pagas, em dias diferentes e com diferentes finalidades (atinentes, por exemplo, à emissão de certidões negativas), protelando o referido registro.

Outrossim, imperioso ressaltar que houve certo impasse no referido registro, haja vista que, no Cartório, a forma jurídica adotada constava, equivocadamente, no rol de pessoas jurídicas com fins empresariais, o que ia de encontro aos ideais da Economia Popular e Solidária, além de aumentar o valor que seria pago a título de registro. Desse modo, fizeramse necessárias novas diligências no sentido de prestar esclarecimentos perante o cartório, tanto sob a forma escrita (requerimento anexo), quanto na forma oral, culminando com a correta adoção da taxa correspondente às pessoas jurídicas com fins não empresariais.

Após o delongado processo de registro, o qual evidenciou a complexidade e os obstáculos impostos à consolidação e sobrevivência da Economia Popular e Solidária, fez-se necessária a inscrição da sociedade no Cadastro Nacional de Pessoas Jurídicas (CNPJ).

Como já esperado, vários óbices foram encontrados, dentre os quais se destacam a difícil acessibilidade aos serviços da Receita Federal, fazendo-se necessária a aquisição de uma senha de atendimento que, além de relacionar-se a períodos distantes, tinha que ser 
obtida por meio eletrônico, no site da Receita Federal, o que, por si só, já dificulta o acesso da população, vez que nem todos os demandantes têm conhecimento e/ou acesso aos meios eletrônicos.

No caso específico da COPERMASOL, prestou-se o devido apoio e auxílio, viabilizando a aquisição de referida senha, ainda que para data distante. Ocorre que, chegada a data agendada, apesar do correto comparecimento das integrantes e da pesquisadora, o serviço havia sido suspenso, nos sendo informado que "os servidores estavam em um curso". Fomos instruídas, então, a comparecer em data posterior, com a mesma senha.

Acontece que, apesar de os servidores estarem em serviço na nova data indicada, o serviço também não foi prestado, sob o argumento de que se faziam necessários outros documentos (além do registro da sociedade em questão), o que em momento algum foi esclarecido pelos funcionários do referido órgão, em que pese os reiterados comparecimentos do grupo. Fazia-se necessário, também, o Documento Básico de Entrada (DBE) e a Ficha Cadastral de Pessoa Jurídica (FCPJ). Nesta oportunidade, verificou-se a necessidade de um acompanhamento contábil para aquisição dos referidos documentos.

Nesse trilhar, as integrantes da COPERMASOL optaram por realizar os serviços com um contador de sua relação pessoal, sob alegação de que o processo seria mais fácil e menos oneroso. A partir deste momento, a formalização entrou num período de estagnação. Em verdade, não era perceptível um desejo inconteste por parte de todas integrantes quanto à formalização, especialmente por conta de conflitos internos, os quais colocavam em dúvida o futuro da sociedade. Ademais, o receio quanto à tributação e responsabilizações futuras decorrentes do contrato eram evidentes, mesmo com as instruções e acompanhamento por parte dos integrantes da IEPS-UEFS.

Nesse diapasão, em comum acordo com os demais integrantes da IEPS-UEFS, estendeu-se o período de incubação do referido grupo e optou-se pela interrupção do processo de formalização, dando margem ao fortalecimento e à comunhão do grupo, protelando os aspectos jurídico-formais para mais adiante, com o auxílio da pesquisadora, a qual atuará de forma voluntária.

\section{CONSIDERAÇÕES FINAIS (ou Conclusão)}

A ausência de um marco legal compatível com os princípios da Economia Popular e Solidária certamente não é uma coincidência. O Direito brasileiro é capitalista, clarividentemente construído para atender os interesses das camadas mais favorecidas da sociedade, configurando-se inacessível para a maior parte da população.

Ainda assim, indubitável o papel da formalização jurídica como instrumento de sobrevivência e consolidação da Economia Popular e Solidária, podendo contribuir para o fortalecimento da reação ao capitalismo e ao seu corolário. É imperioso ressaltar que tal finalidade só é alcançada quando os princípios da Economia Popular e Solidária encontram-se assentes nos grupos que dela se utilizam, evitando, assim, que a formalização caminhe na contramão, revigorando a segregação social capitalista por meio de "ilegítima" ordenação solidária. 
O processo de formalização instigado pela pesquisadora ainda não se findou. Com efeito, após a consolidação da COPERMASOL, tal projeto será retomado, auxiliando na viabilização do regular funcionamento do grupo, especialmente no período da pós incubação, garantindo a conquista e exercício dos devidos direitos pelas suas integrantes.

\section{REFERÊNCIAS}

PITA, F.A. Formalização jurídica e economia popular e solidária: reflexões a partir de uma experiência de incubação. Anais do $8^{\circ}$ Congreso Chileno de Sociología y Encuentro PreALAS, Chile, 2014.

GAIGER, L. I. G. A economia solidária diante do modo de produção capitalista. Disponível em: $<$ http://www.ecosol.org.br $>$. Acesso em: 30 de jun. 2016.

LIMA, T.N.S. A ausência de um marco legal e de uma legislação específica para os grupos que atuam na economia solidária. Monografia (Trabalho de Conclusão do Curso de Direito). Universidade Estadual de Feira de Santana, Feira de Santana, Brasil, 2012.

Série Pensando o Direito. Regime Jurídico de Cooperativas Populares e Empreendimentos de Economia Solidária. Núcleo de Economia Solidária da Universidade de São Paulo (NESOLUSP), 2012.

VIEIRA, A.C.M. Desafios a formalização legal de empreendimentos solidários. Faculdade de Pindamonhangaba, São Paulo. Disponível em: http://www.conpes.ufscar.br/wpcontent/uploads/trabalhos/gt8/sessao-5/vieira-arlete-candido-monteiro.pdf. Acesso em 05 de julho de 2016. 